\title{
Optimization of Municipal Solid Waste Management of Bins Using GIS. A Case Study: Nuseirat City
}

\author{
Maher A. El-Hallaq1 ${ }^{1}$, Rami Mosabeh ${ }^{2}$ \\ ${ }^{1}$ Islamic University of Gaza, Gaza, Palestine \\ ${ }^{2}$ United Nations Development Programme, Gaza, Palestine \\ Email:mhallaq@iugaza.edu.ps, ramimosabeh@gmail.com
}

How to cite this paper: El-Hallaq, M.A. and Mosabeh, R. (2019) Optimization of Municipal Solid Waste Management of Bins Using GIS. A Case Study: Nuseirat City. Journal of Geographic Information System, 11, 32-43.

https://doi.org/10.4236/igis.2019.111003

Received: December 18, 2018

Accepted: February 9, 2019

Published: February 12, 2019

Copyright () 2019 by author(s) and Scientific Research Publishing Inc. This work is licensed under the Creative Commons Attribution International License (CC BY 4.0).

http://creativecommons.org/licenses/by/4.0/

\begin{abstract}
Solid Waste Management, SWM, is an integral part of public health and environmental control. Improper SWM leads to both economic and environmental sufferings. Almost all factors related to solid waste management have both spatial and non-spatial components. Thus, traditional ways of storing and analyzing data keep data in an isolated form, which results in an inefficient management system. This research aims to optimize municipal solid waste management of bins using GIS. Nuseirat City is chosen as a case study to evaluate SWM of recycle bins to allow the collection process to get less cost and less time as well as to determine the best routes for the trucks to collect the bins. Using Location-Allocation technique, the study indicates that 50 bins from the existing 222 bins do not meet the required selection criteria and need to be re-distributed. It also shows that there are many areas which are not serviced and that the existing bins do not cover all areas in Nuseirat. $\mathrm{Nu}-$ seirat municipality needs to supply 173 bins besides the existing bins in order to fully cover the city. Moreover, the best tracks to be followed by vehicles that will reduce the financial cost using Vehicle Routing Problem Analysis are determined using GIS network analysis. It is recommended the use of GIS in the administration, especially the management of solid waste and the consideration of it mainly in the general system of municipalities working in the Gaza Strip. Extensive attention should be focused on the collection of solid waste because it is important in the development of cities and it gives a wonderful cultural landscape.
\end{abstract}

\section{Keywords}

Solid Waste, Municipal Management, GIS, Nuseirat City 


\section{Introduction}

SWM includes control of generation, storage, collection, transport, processing and disposal of waste. The collection, transport, treatment, and disposal of solid wastes, particularly wastes generated in medium and large urban centers, have become a relatively difficult problem to solve for those responsible for their management [1]. Increasing population levels, booming economy, rapid urbanization and the rise in community living standards have greatly accelerated the municipal solid waste generation rate in developing countries [2]. In African cities, for example, poor management of solid waste is a common phenomenon due to budgetary problems, mismatching plans and inadequate information about the amount of solid waste generated by residents [3].

At the same time, improper handling and disposal of solid waste constitutes a serious problem: it results in deterioration of the urban environment in the form of air, water, and land pollution [4] [5]. That poses risks to human health and causes serious environmental problems. The problem is even more acute in economically developing countries, where financial, human, and other critical resources generally are scarce. One important contribution to the difficulties related to waste management is that which can be achieved by providing objective, reliable, and useful information to professionals in developing countries and to those from industrialized countries who may be called upon to aid those countries [1]. Inadequate management of solid waste in most cities of developing countries leads to problems that impair human and animal health and ultimately result in economic, environmental and biological losses [6].

Almost all factors related to SWM have both spatial and non-spatial components. Thus, traditional ways of storing and analyzing data keep data in an isolated form, which results in an inefficient management system. A number of studies introduce the use of GIS in the field of SWM [7]-[12]. Through different case studies and discussions, they demonstrate the aid of GIS in areas related to SWM, especially in collection, and choose the optimize route for collection process, to increase system efficiency, reduce workload, save time and cost, as well as assisting in decision support. They also concentrate in three different operations of SWM, which are waste storage, waste collection, and waste disposal.

\section{Location-Allocation GIS Technique}

Given facilities that provide services and a set of demand points that consume them, the goal of Location-Allocation is to locate the facilities in a way that supplies the demand points most efficiently. As the name suggests, Location-Allocation is a twofold problem that simultaneously locates facilities and allocates demand points to the facilities [13]. Location is often considered the most important factor leading to the success of a private- or public-sector organization.

Private-sector organizations can profit from a good location, whether a small coffee shop with a local clientele or a multinational network of factories with 
distribution centers and a worldwide chain of retail outlets. Location can help keep fixed and overhead costs low and accessibility high. Public-sector facilities, such as schools, hospitals, libraries, fire stations, and emergency response services centers, can provide high-quality service to the community at a low cost when a good location is chosen [13]. Initially, it may appear that all Location-Allocation analyses solve the same problem, but the best location is not the same for all types of facilities. For instance, the best location for an emergency response services center is different from the best location for a manufacturing plant. Many examples can demonstrate how the goals of Location-Allocation problems vary according to the type of facility being located.

The ArcGIS Location-Allocation analysis layer offers six different problem types to answer specific kinds of questions. The six problem types are: Minimize impedance, maximize coverage, minimize facilities, maximize attendance, maximize market share and target market share. In our case, solid waste bins represent the public facilities that are taken into study consideration and the maximize coverage type is used.

\section{SWM in Gaza Strip}

Waste management services in Gaza Strip are currently under great stress, as most other public services, due to the permanent closure of Gaza Strip and the very bad economic circumstances in which the people in Gaza live. In 2018, the population of Gaza Strip was about 2.0 Million. Based on population projections made by the Palestinian Central Bureau of Statistics, it may be expected that this population will grow to 3.2 Million in the year 2040. An assessment of the per capita waste generation shows that the total amounts of household waste generated by this population will likely rise from 1506 ton/day in 2011 to 3383 ton/day in 2040 [14].

Solid waste management in Gaza Strip is currently performed by the following five waste services providers; North Gaza Joint Service Council, Gaza Municipality, Deir Al-Balah Joint Service Council, Rafah Municipality, and UNWRA. Scarcity of waste disposal sites coupled with huge increase in waste generation is leading to serious environmental and human health impacts on the population. The severity of the crisis is a direct consequence of continuing blockade and lack of financial assistance from international donor.

There are three landfills in Gaza Strip; one each in southern and central part of Gaza and one in Gaza governorate. In addition, there are numerous unregulated dumpsites scattered across rural and urban areas which are not fenced, lined or monitored. Domestic, industrial and medical wastes are often dumped near cities and villages or burned and disposed of in unregulated disposal sites which cause soil, air and water pollution, leading to health hazards and ecological damage. The physical damage caused to Gaza's infrastructure by repeated aggression has been a major deterred in putting forward a workable solid waste management strategy in the Strip. There is lack of studies regarding solid waste 
management either in the governmental level or in the academic level. Thus, this study will be a step on the right way.

\section{Case Study: Nuseirat City}

Nuseirat is a Palestinian refugee camp located five kilometers north-east of Deir Al-Balah City. The refugee camp is in the Middle Area Governorate. It is east bordered by Salah Al-Din Street and Bureij Camp, Mediterranean Sea to the West, Al-Zahraa City to the north and Al-Zwayda City to the south. Figure 1 shows the boundary of Nuseirat Municipality. According to the Palestinian Central Bureau of Statistics, the Refugee Camp had a population of 86,135 in mid-year 2016 [15]. Population density is maintained at three levels (low, medium, high) and the city is classified into four zones (Figure 2).

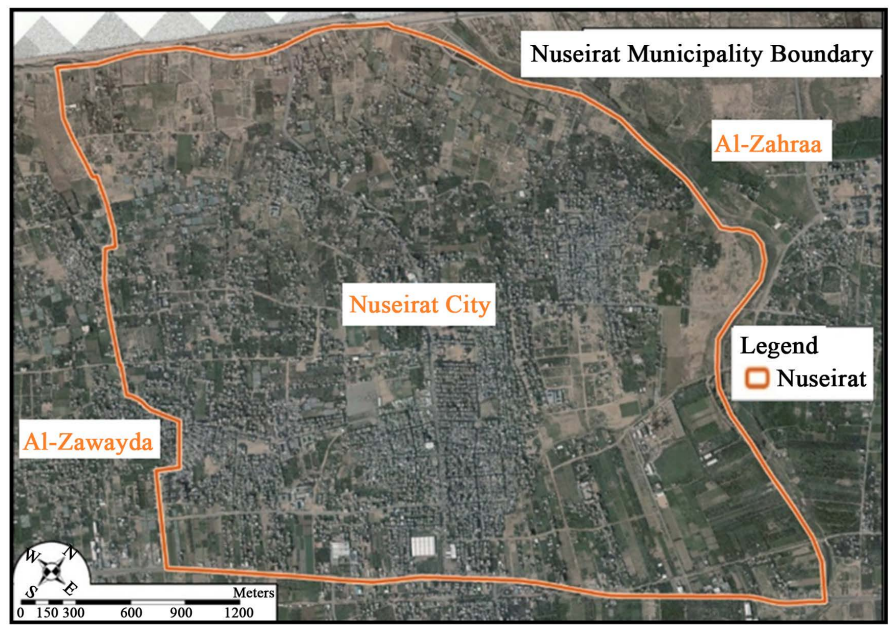

Figure 1. The boundary of Nuseirat City.

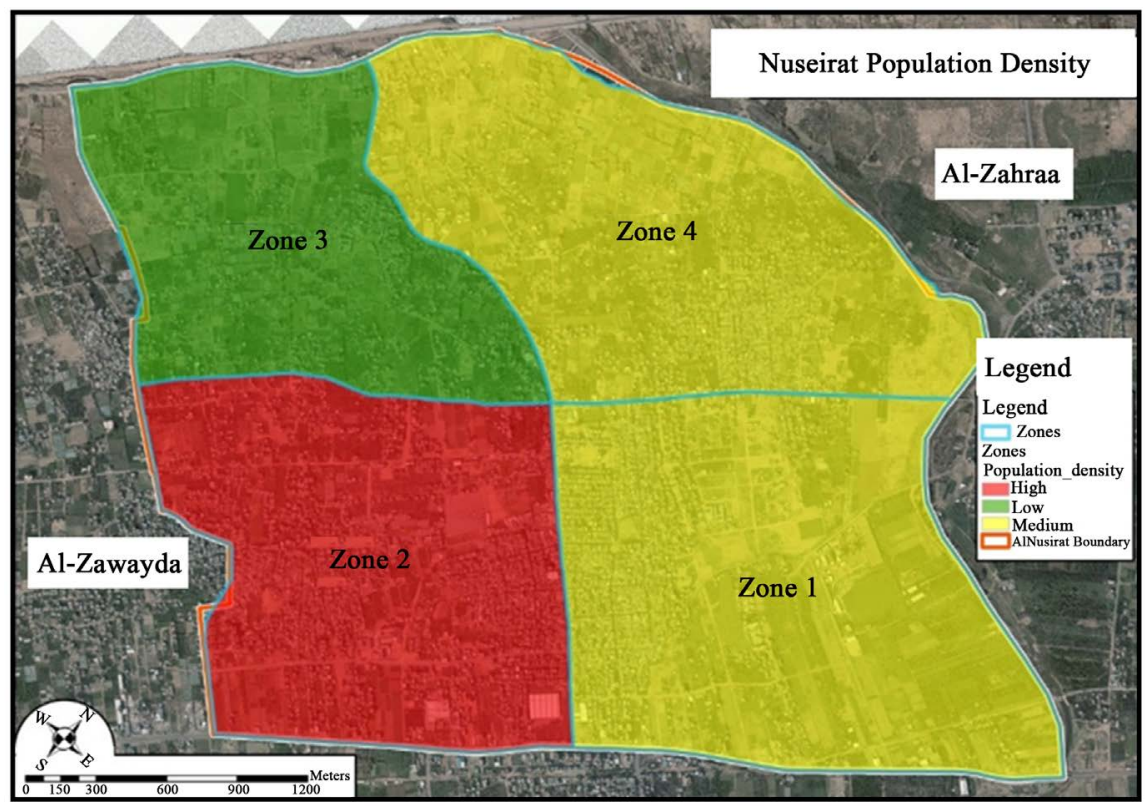

Figure 2. The zones of Nuseirat City. 
Nuseirat is involved in Deir Al-Balah Joint Service Council which covers 13 municipalities in the middle region of Gaza Strip, including Khan Younis City. Deir Al-Balah Joint Service Council collects waste from approximately 2900 containers located along the streets of these municipalities. In addition, the municipalities themselves organize door-to door collection using donkey carts supported by a collection fleet consisting of tipper cranes, compactor trucks and tractors. Bad conditions of the collection fleet and limited financial resources are major constraints to these operations, and sometimes waste is piled up at temporary and unprotected storage sites for long periods of time. Moreover, many inhabitants complain that the waste bins are not appropriate and random dumps scattered throughout the province. Thus, the study aims to optimize Nuseirat municipal solid waste management of bins using GIS. This involves spatially evaluating the current status of the collecting bins distribution, redistributing the recycle bins to allow the collection process getting less cost and time as well as locating the best pathway for the trucks to collect the bins.

\section{Methodology}

Figure 3 illustrates the methodology framework for the optimization and management of collecting solid waste bins by using Location-Allocation technique within GIS software. It consists from four consecutive stages; data collection, GIS evaluation, analysis, and conclusion and recommendations. Each stage involves several tasks as shown below.

\subsection{Data Collection}

In order to carry out the analysis, the data needed for the analysis process must be collected and added in successive layers to produce an appropriate bin distribution, including the roads layer, the building layer, the existing bins layer and the subzone layer. Table 1 summarizes the attribute data in each layer class.

Once the geographic database is ready for analysis, The ESRI ArcMap software will be moved on to another interface of the analysis process integration so that the sequences can be followed through. Figure 4 shows the required data manipulated in this study.

Table 1. Attribute data in each layer.

\begin{tabular}{|c|c|c|}
\hline Layer name & Layer type & Cartography data \\
\hline Building layer & Polygon & $\begin{array}{ll}\text { - } & \text { Number } \\
\text { - } & \text { Address } \\
\text { - } & \text { Number of individuals } \\
\text { - } & \text { Solid waste quantity (liter) }\end{array}$ \\
\hline Roads layer & Line & $\begin{array}{ll}\text { - } & \text { Street number } \\
\text { - } & \text { Street name } \\
\text { - } & \text { Speed } \\
\text { - } & \text { Status } \\
\text { - } & \text { Length }\end{array}$ \\
\hline Existing bins layer & Point & $\begin{array}{ll}\text { - } & \text { Bin number } \\
\text { - } & \text { Location } \\
\text { - } & \text { Capacity }\end{array}$ \\
\hline
\end{tabular}




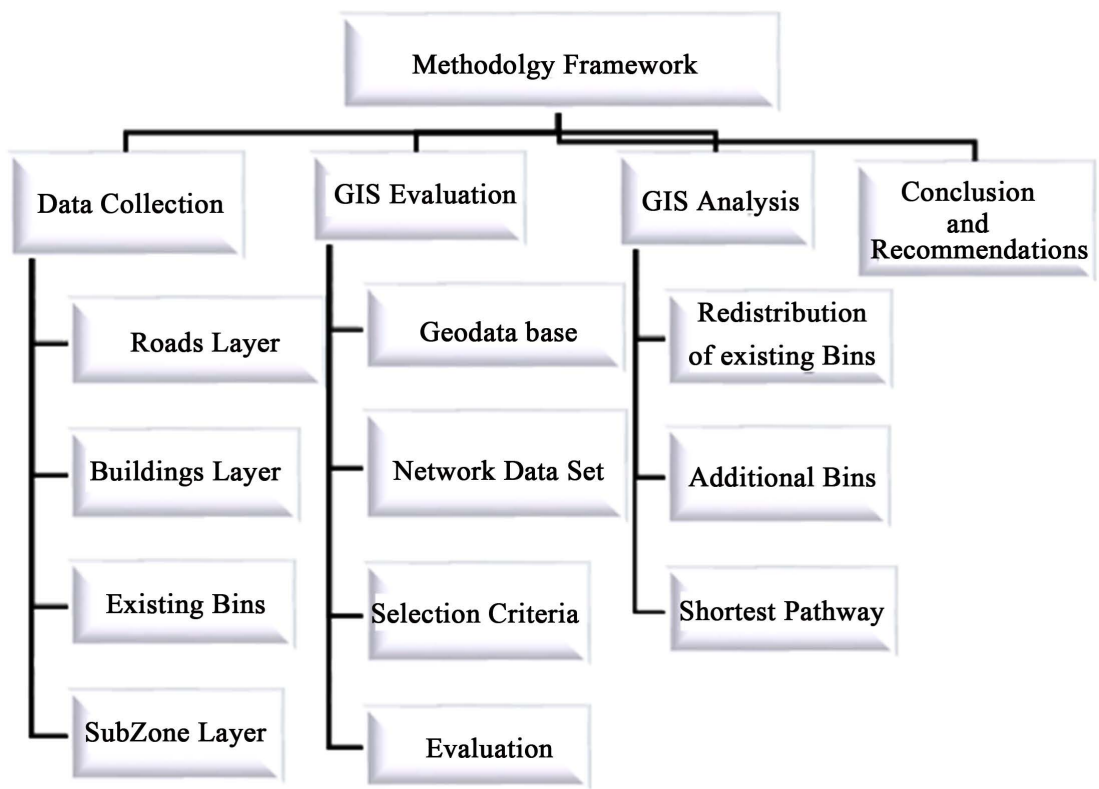

Figure 3. Methodology stages and tasks.

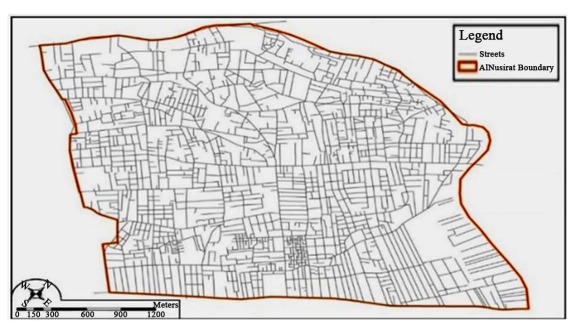

(a)

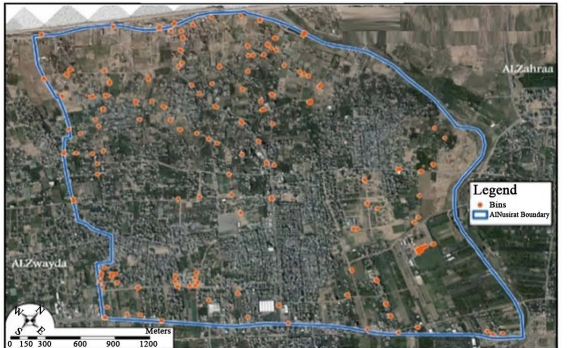

(c)

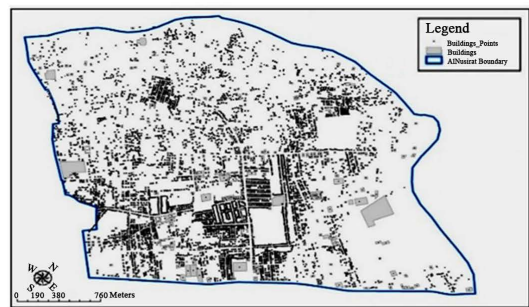

(b)

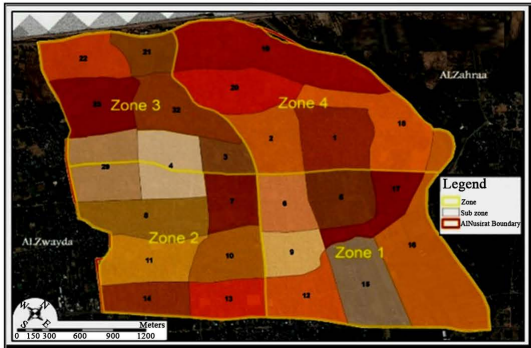

(d)

Figure 4. The layers needed for analysis. (a) Roads layer; (b) Building layer; (c) Existing bins layer; (d) Subzone layer.

\subsection{GIS Evaluation Stage}

Many sequences are required to apply the GIS tool for Network analysis. After data collection stage completion, the essential elements of distributed bins must be prepared like the distance between building and bin, bin capacity, expected solid waste quantity per building and average solid waste production per capita. Next, Location-Allocation must be applied and passed through specific sequences like geographic database, establishment of network database included by road network specifications. The selection criteria for analysis are based on the following: 
1) Considering the type of a problem is maximize capacity coverage.

2) The number of existing bins to be included in the analysis is 222 bins.

3) The maximum distance between any building and the corresponding bin is $120 \mathrm{~m}$.

4) Assuming the capacity of the virtual bin is 1000 liters.

5) Choosing the Power equation.

Once after the criteria selection process is determined, the evaluation analysis using GIS tools can be applied, and the results is shown in Figure 5. It indicates that 50 bins from the existing 222 bins do not meet the required conditions and need to be re-distributed. It also shows that there are many areas are not serviced and that the existing bins do not cover all areas in Nuseirat according to the previous selection criteria.

\subsection{GIS Analysis Stage}

The analysis must be applied after adding the necessary databases as mentioned above. It should be carried out to produce the best bins distributions to cover all the Nuseirat City. The analysis should be done through determination of the facilities by selecting the bins layer which contains the actual data in Nuseirat with the characteristics of the layer like facility type candidate and capacity of bins. To make the redistribution for the bins to the suitable status, service zone analysis should be made to reach the optimization for the bin's distribution. Table 2 shows the unmanaged subzones and the number of unserved buildings located in each one.

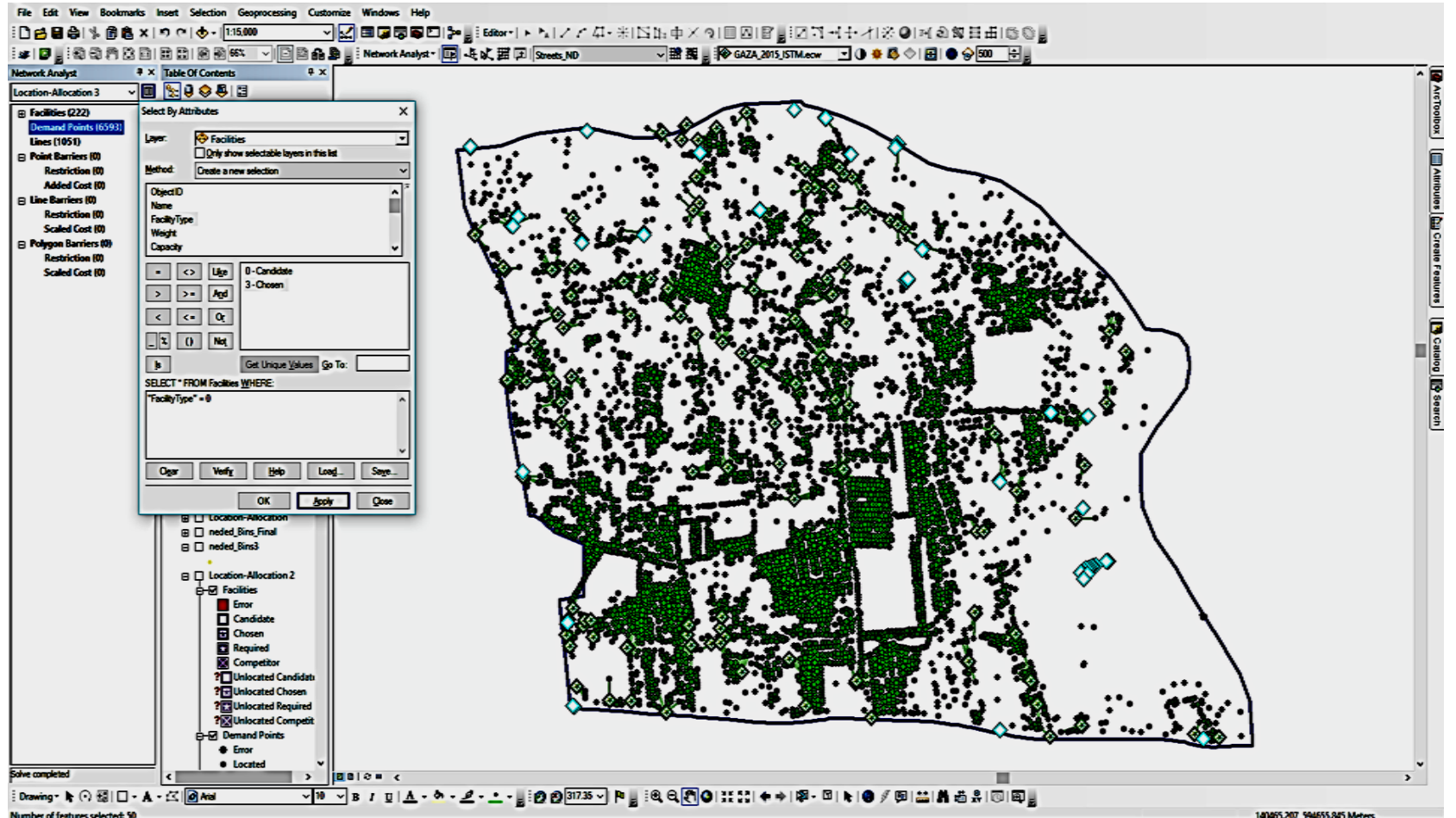

Figure 5. The evaluation results of the existing bins. 
Table 2. Service zone in Nuseirat.

\begin{tabular}{|c|c|c|c|c|c|c|c|}
\hline Zone & Subzone & No. of buildings & Served & Zone & Subzone & No. of buildings & Served \\
\hline \multirow{7}{*}{1} & 5 & 242 & Yes & \multirow{7}{*}{3} & 3 & 137 & No \\
\hline & 6 & 474 & No & & 4 & 311 & No \\
\hline & 9 & 255 & No & & 21 & 28 & Yes \\
\hline & 12 & 320 & No & & 22 & 61 & No \\
\hline & 15 & 185 & Yes & & 23 & 150 & Yes \\
\hline & 16 & 70 & No & & 29 & 271 & Yes \\
\hline & 17 & 52 & No & & 32 & 370 & Yes \\
\hline \multirow{6}{*}{2} & 7 & 185 & Yes & \multirow{6}{*}{4} & 1 & 455 & No \\
\hline & 8 & 577 & No & & 2 & 191 & No \\
\hline & 10 & 693 & No & & 18 & 259 & Yes \\
\hline & 11 & 472 & Yes & & 19 & 258 & Yes \\
\hline & 13 & 265 & No & & 20 & 186 & Yes \\
\hline & 14 & 166 & Yes & & & & \\
\hline
\end{tabular}

It is necessary to increase the number of bins, to promote the use of this type of collection, to set the best places for bins in addition to identify the required bins, which can cover all parts of the city through the re-analysis based on the number of virtual bins by putting points on the road network every $120 \mathrm{~m}$ and the use of the same previous criteria taking into account the capacity of each bin as 1000 liters.

Figure 6 shows the distribution and the total number of needed bins to make a well coverage in the whole City. It indicates that 611 bins are required. The analysis shows 216 bins with no more than 300 liters of waste. Therefore, they will be excluded and promising to distribute the surrounding bins in the adjacent area so that they become more suitable. This is done by setting the field locations and evaluating the most appropriate places. The actual existing number of bins in Nuseirat is 222 bins. The total number of bins that the municipality needs in order to fully cover the city are 395 bins based on the standard requirements that should be applied according to the selection criteria. Thus, Nuseirat municipality needs to supply and add 173 bins.

\subsection{Vehicle Routing Problem Analysis}

The process of collecting waste through bins is considered a relatively expensive method, but it is the best way to preserve the environment and protect it from pollution. The most important elements that contribute to reducing the financial cost of the collection process are choosing the appropriate tracks for the vehicles so that the collections process is more efficient and less expensive. The Key elements of the waste collection process are shown in Figure 7. 


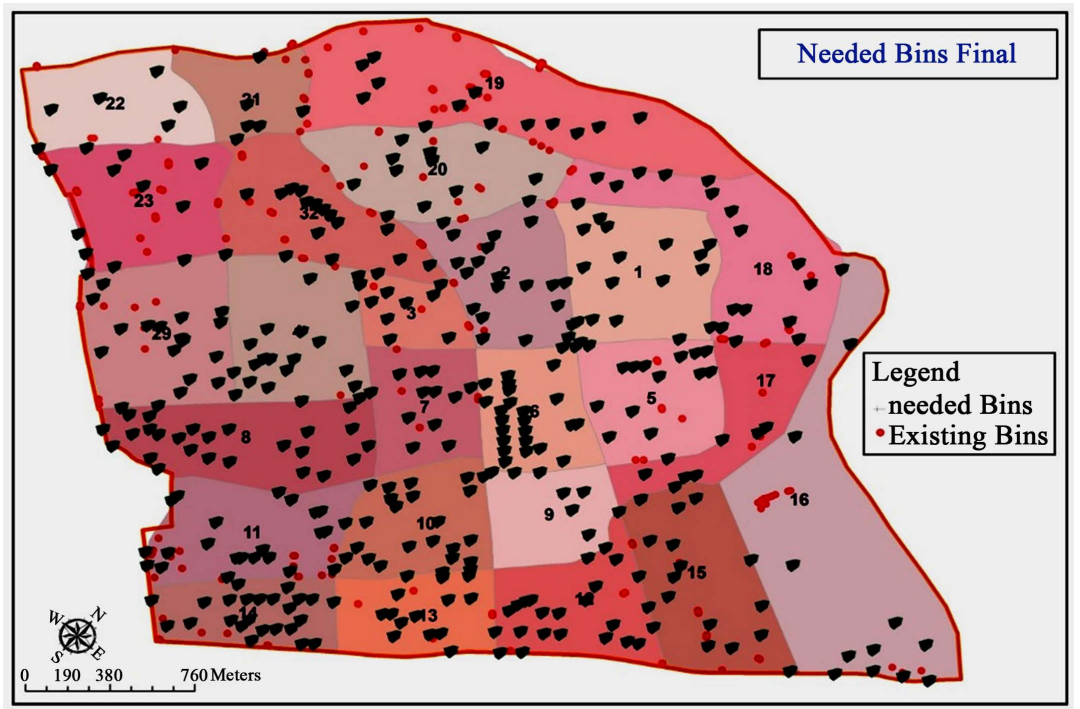

Figure 6. The needed bins for full coverage.

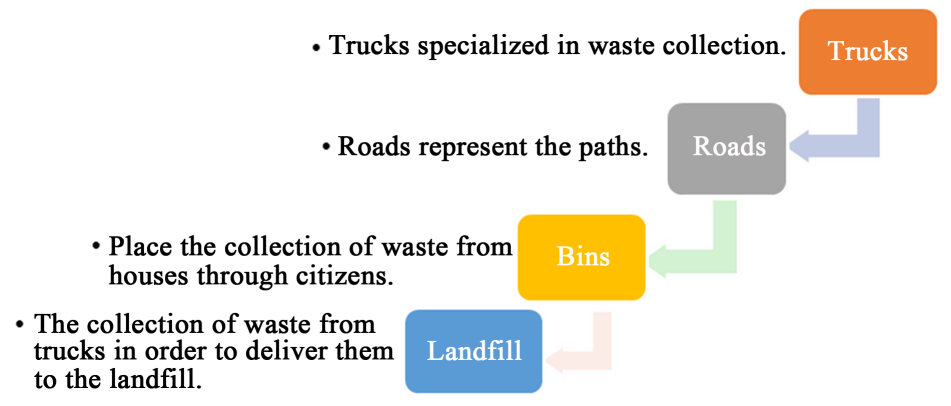

Figure 7. Key elements of the waste collection process.

Using GIS technology can identify the best tracks to be followed by vehicles that will reduce the financial cost using Vehicle Routing Problem Analysis. To do this type of network analysis, in order to carry out the analysis for the best pathway, the following steps should be implemented in sequence through a set of concepts that must be understood, including:

1) Orders: It is the bins to deliver services. The bins layer is imported by analyzing Location-Allocation and specifying its different properties such as name, time of service, start of work, end of work, amount of waste collected and many other characteristics.

2) Depots: They represent the main dumps where the trucks will unload their cargo so that they will start from it and then return to it. Here, their special characteristics will be set: landfill, work hours, delay time, etc.

3) Routs: It means the trucks that will be responsible for transporting the waste and delivering it to the landfill and has many characteristics that must be set.

4) Route Zone: It is used to determine the path of each truck. Here, Nuseirat is divided into four main zones to represent the scope of work for each vehicle.

After processing the previous 4 steps, the properties of analysis are modified, 
and the calibration is set to be relied upon during the analysis such as time, unit distance and distance. Figure 8 shows the track for each truckload of trucks passing through number of bins while Figure 9 shows the exhibition of the 4 truck routes.

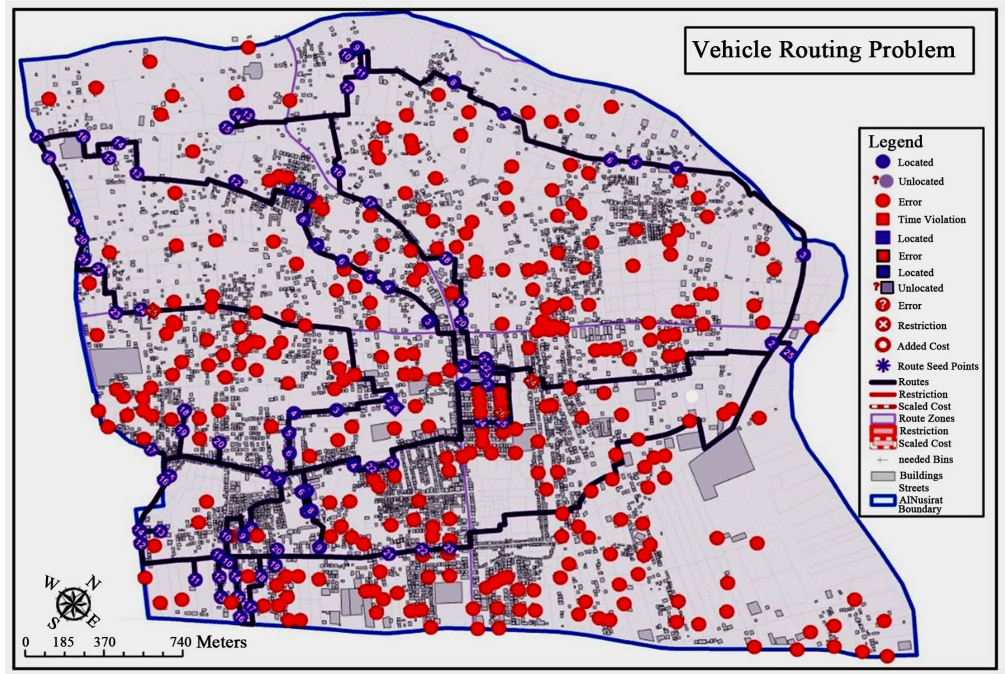

Figure 8. Analysis result for vehicle routing problem.

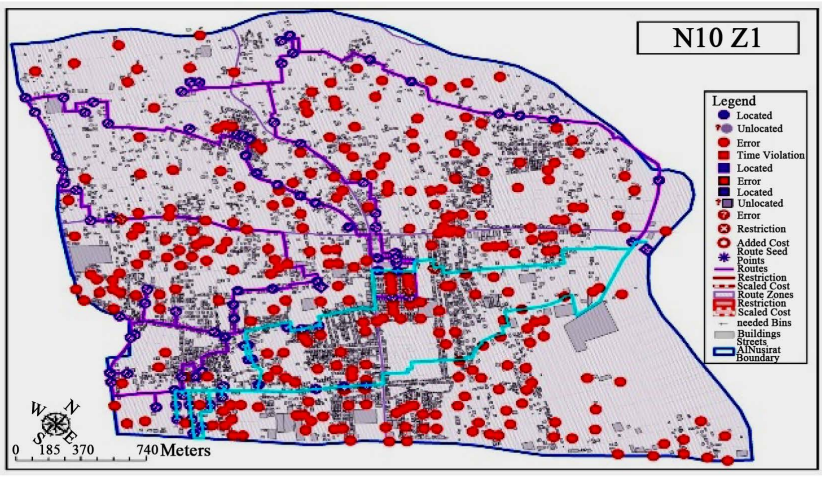

(a)

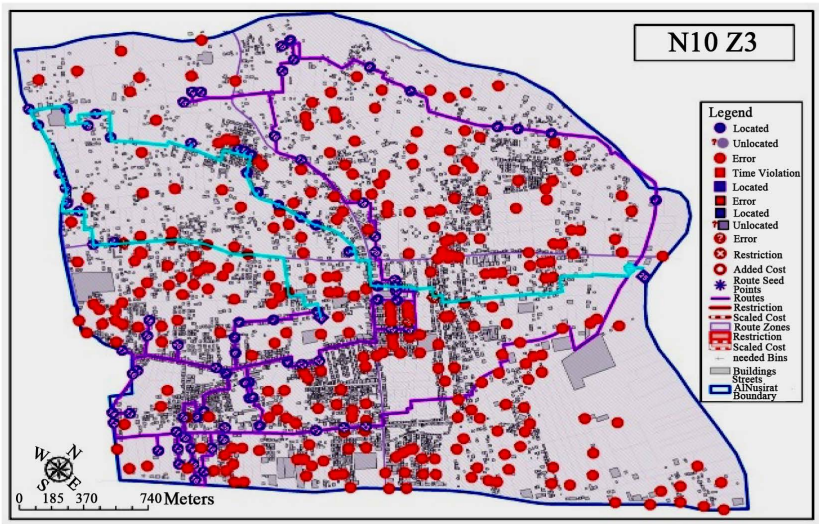

(c)

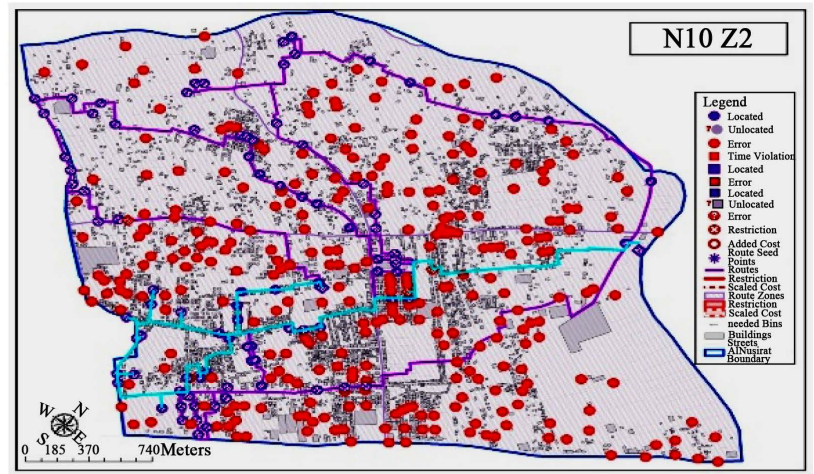

(b)

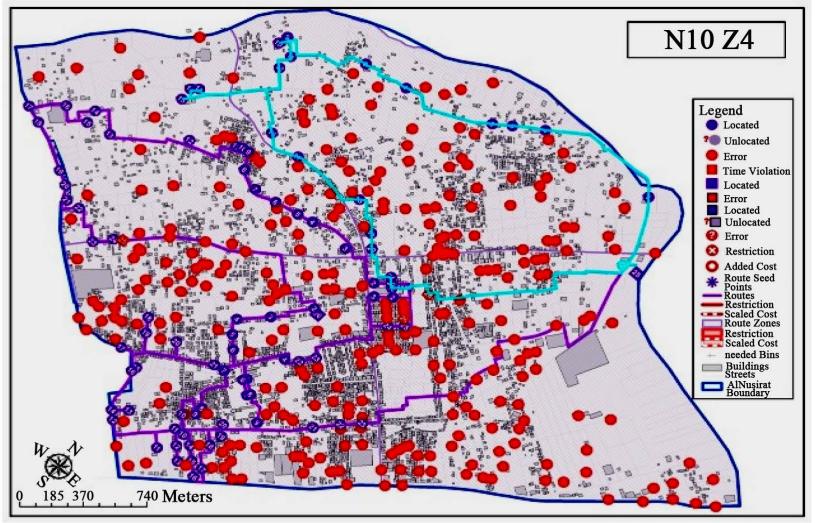

(d)

Figure 9. The exhibition of the 4 truck routes. (a) Route for the first truck; (b) Route for the second truck; (c) Route for the third truck; (d) Route for the fourth truck. 


\section{Conclusion and Recommendations}

Network analysis is one of the most important types of spatial analysis whose applications are varied to include different aspects of life. In this study, Location-Allocation GIS tool is used to evaluate the current distribution of solid waste bins in Nuseirat City. It indicates that the existing 222 bins are placed in improper locations and its number is insufficient to cover all City zones. For this purpose, 173 additional bins are required with a re-distribution process to meet the standard criteria. Moreover, Vehicle Routing Problem Analysis is used to identify the best tracks that should be followed by solid waste collecting vehicles to reduce the financial cost. It is strongly recommended that regular meetings among representatives from all Gaza Strip municipalities, at the governorate level, who are concerned with solid waste management. This will help managers to develop coordination, cooperation, share experiences and discuss mutual problems. Each municipality must revise the distribution and efficiency of its solid waste bins and start using GIS as a management tool to make an effective system for the collection process.

\section{Conflicts of Interest}

The authors declare no conflicts of interest regarding the publication of this paper.

\section{References}

[1] UNEP (United Nations Environment Programme) (2005) Solid Waste Management. Vol. 1, ISBN: 92-807-2676-5.

[2] Minghua, Z., Xiumin, F., Rovetta, A., Qichang, H., Vicentini, F., Bingkai, L. and Yi, L. (2009) Municipal Solid Waste Management in Pudong New Area, China. Waste Management, 29, 1227-1233.

[3] Simelane, T. and Mohee, R. (2012) Future Directions of Municipality Solid Waste Management in Africa Pretoria. https://www.africaportal.org/content-partners/

[4] Adekunle, I.M., Adebola, A.A., Aderonke, K.A., Pius, O.A. and Toyin, A.A. (2011) Recycling of Organic Wastes through Composting for Land Applications: A Nigerian Experience. Waste Management \& Research, 29, 582-593.

[5] Jalil, A. (2010) Sustainable Development in Malaysia: A Case Study on Household Waste Management. Journal of Sustainable Development, 3, 91-102.

[6] Sharholy, M., Ahmad, K., Mahmood, G. and Trivedi, R.C. (2008) Municipal Solid Waste Management in Indian Cities-A Review. Waste Management, 28, 459-467.

[7] Aremu, A.S. (2011) Optimization and Assessment of Waste Bin Locations Using Geographic Information System. Proceedings of the 3rd Annual Civil Engineering Conference, University of Ilorin, Ilorin, 2011, 231-236.

[8] Verma, A. and Bhonde, B.K. (2014) Optimisation of Municipal Solid Waste Management of Indore City Using GIS. International Journal on Emerging Technologies, 5, 194-200.

[9] Chalkias, C. and Lasaridi, K. (2009) A GIS Based Model for the Optimization of Municipal Solid Waste Collection: The Case Study of Nikea, Athens, Greece. Harokopeio University of Athens, Athens. 
[10] Purkayastha, D., Majumder, M. and Chakrabarti, S. (2015) Collection and Recycle Bin Location-Allocation Problem in Solid Waste Management: A Review. Pollution, 1, 175-191.

[11] Vijay, R., Gautam, A., Kalamdhad, A., Gupta, A. and Devotta, S. (2008) GIS Based Locational Analysis of Collection Bins in Municipal Solid Waste Management System. Journal of Environmental Engineering and Science, 7, 39-43.

[12] Sumedh, D., Kashid, D.B., Nalawade, A.D., Nagne, R.K. and Dhumal, K.V.K. (2015) Solid Waste and Waste Bin Management by Using RS \& GIS: A Review. International Journal of Scientific \& Engineering Research, 6, 554-557.

[13] ESRI (Environmental Systems Research Institute) (2015) https://www.esri.com

[14] UNDP (United Nations Development Programme) (2012) Feasibility Study and Detailed Design for Solid Waste Management in the Gaza Strip. DHV ENFRA TECC.

[15] PCBS (Palestinian Central Bureau of Statistics) (2018) Localities in Deir al Balah Governorate by Type of Locality and Population Estimates, 2007-2016.

http://www.pcbs.gov.ps/site/lang_ar/803/default.aspx 